\title{
Desempenho de estudantes baianos nas estruturas multiplicativas: uma visão quantitativa dos fatos
}

\author{
Sandra Maria Pinto Magina \\ Sônia Pereira da Fonseca
}

\section{Resumo}

Este artigo tem por objetivo apresentar os principais resultados quantitativos dos 4076 estudantes participantes do projeto de pesquisa intitulado "As estruturas multiplicativas e a formação de professores que ensinam matemática na Bahia" (FAPESB PESoo19/2013) ao resolverem 14 situaçõesproblema de um instrumento diagnóstico. Esses estudantes são advindos de oito cidades baianas distintas, a saber: Ilhéus, Itabuna, Jequié, Vitória da Conquista, Amargosa, Feira de Santana, Salvador e Senhor do Bonfim. As situações-problema foram todas construídas a partir de uma releitura do Campo Conceitual Multiplicativo (VERGNAUD 1983, 1994) proposta por Magina e Cols. (2014, 2016). Os resultados apontam para uma grande fragilidade desses estudantes nos conceitos das estruturas multiplicativas e sugere que sejam adotadas políticas públicas, estaduais e municipais, na direção de ampliar a formação dos conceitos pertencentes às estruturas multiplicativas dos estudantes baianos.

Palavras Chaves: Estrutura Multiplicativa; Estudo Diagnóstico; Ensino Fundamental; Projeto de Pesquisa 


\title{
Performance of Bahia students in multiplative structures: a quantitative view of the facts
}

\author{
Sandra Maria Pinto Magina
}

Sônia Pereira da Fonseca

\section{Abstract}

This article aims to present the main quantitative results from 4076 students who had being participated in the research project entitled "The multiplicative structures and the training of teachers who teach mathematics in Bahia" (FAPESB PESo019/2013) when solving 14 problems of a diagnostic instrument . These students come from eight different Bahia cities, namely: Ilhéus, Itabuna, Jequié, Vitória da Conquista, Amargosa, Feira de Santana, Salvador and Senhor do Bonfim. The problems were all constructed from a re-reading, proposed by Magina and Cols. $(2014,2016)$, concerning of the Multiplicative Conceptual Field (VERGNAUD 1983, 1994). The results point out to the great fragility of these students in the concepts of multiplicative structures and suggests that public, state and municipal policies be adopted in order to expand the formation of the concepts belonging to the multiplicative structures of the students of Bahia.

Keywords: Multiplicative Structures; Diagnostic Study; Elementary school;

Research Project 


\section{Introdução}

Este artigo tem por objetivo apresentar e discutir os resultados quantitativo advindos da aplicação de um instrumento diagnóstico, composto por 14 situações-problema do campo conceitual multiplicativo, em 4.076 estudantes baianos que cursavam entre $01^{\circ}$ e o $9^{\circ}$ ano do Ensino Fundamental. Tal instrumento foi elaborado no âmbito do projeto "As Estruturas Multiplicativas e a Formação de Professores Baianos” (FAPESB, PESoo19/2013).

O projeto foi realizado em rede, envolvendo seis núcleos de pesquisa, a saber: Universidade Estadual de Santa Cruz (núcleo proponente), a Universidade Estadual do Sudoeste da Bahia- Campus Vitória da Conquista (núcleo UESB-Conquista), Universidade do Estado da Bahia, Campus Senhor do Bonfim (núcleo UNEB-Bonfim), Universidade Estadual de Feira de Santana (núcleo UEFS-Feira), a Universidade Federal do Recôncavo da Bahia (núcleo UFRB-Amargosa) e Grupo Educação Matemática em Foco (núcleo ENFoco-Salvador), cada um, por sua vez, trabalhando em parceria com pelo menos uma escola pública. A meta prioritária do projeto foi o de formar professores dessas escolas parceiras no que tange ao campo conceitual multiplicativo. E, para tanto, lançou-se mão da metodologia de formação continuada RePARe (Reflexão, Planejamento, Ação, Reflexão), que se dá seguindo um modelo representado por uma espiral ascendente, conforme a figura 1 a seguir:

Figura1: A Espiral RePARe, um modelo de formação continuada de professor.

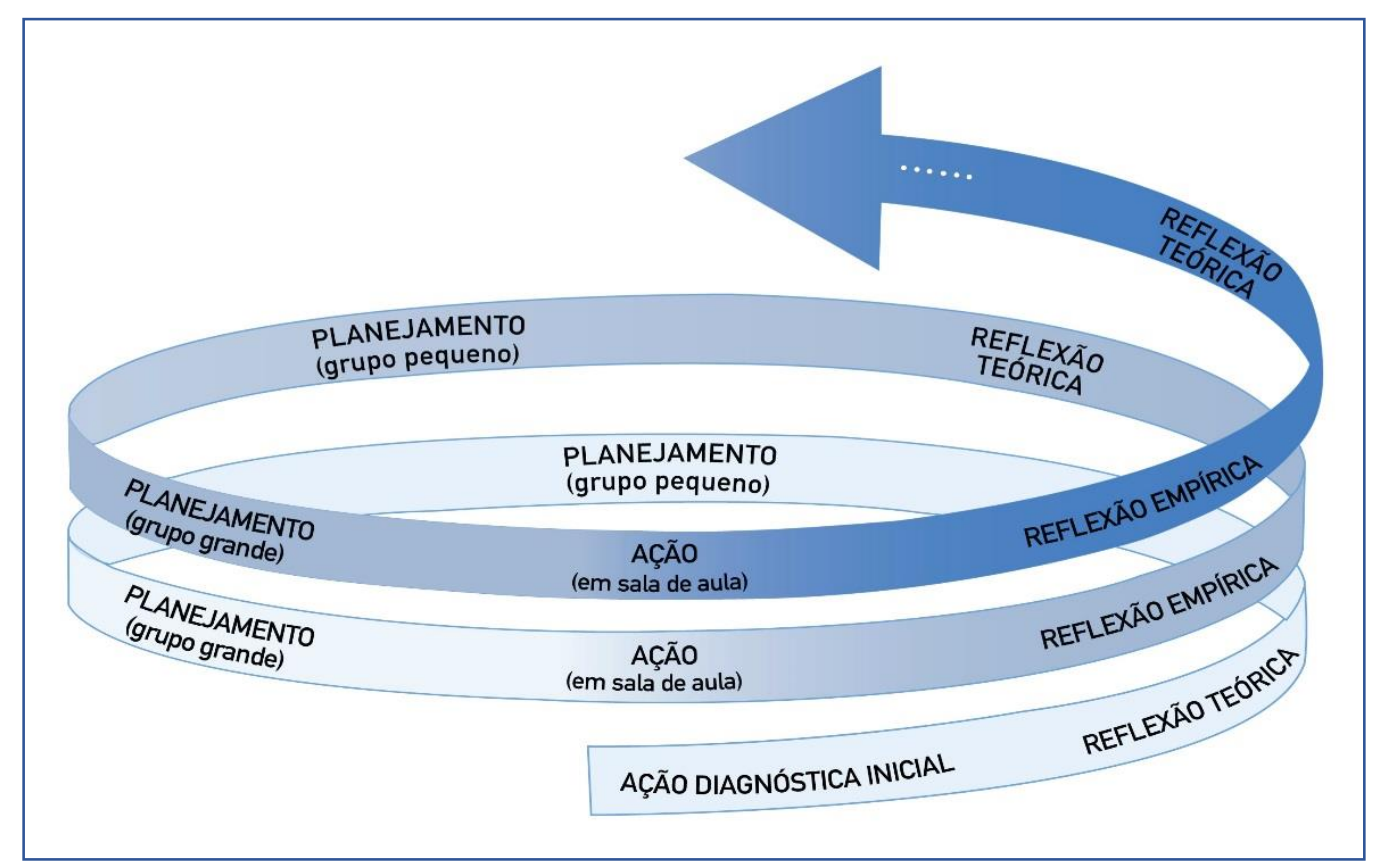

Fonte: Magina, reelaboração adaptativa do $1^{\circ}$ modelo da espiral RePARe (MAGINA, 2008)

Como mostrado na figura 1, o de formação RePARe segue o modelo de uma seta que caminha infinitamente em espiral. É importante entender que cada volta completa da espiral 
significa um ciclo compreendido por três momentos distintos (Reflexão, Planejamento, Ação). No caso do nosso projeto (e também em todos os projetos que usaram tal metodologia até aqui) a formação iniciou-se a partir da discussão dos resultados obtidos pelos os alunos dos professores formandos a um teste (diagnóstico inicial) contendo os conteúdos que se pretendíamos trabalhar na formação. Esses resultados referiam-se às respostas que 4076 estudantes deram às 14 questões do teste.

Para a realização da formação essas respostas (4076 instrumentos vezes 14 situaçõesproblema, igual a 57.064 respostas) foram compiladas e os acertos de cada uma das questões, por ano escolar, desde o $1^{\circ}$ ao $9^{\circ}$ ano, foram relativizados em percentual e, na sequência, transformados em gráficos para serem, gradualmente, apresentados e discutidos nos encontros de formação. Assim a discussão do desempenho dos estudantes no teste foi fatiada segundo o grupo de conceitos que se pretendia trabalhar em cada encontro, procedendo permitindo que os resultados pudessem ser entendidos a luz do campo conceitual multiplicativo (reflexão teórica). Essa reflexão coletiva, por sua vez, servia de base para que os professores formandos se reunissem em pequenos grupos e planejassem duas atividades a serem trabalhadas com seus estudantes em suas salas de aula (planejamento - pequeno grupo) e ainda, dentro do encontro, apresentassem para os demais o que foi planejado, de tal forma que as atividades pudessem sofrer alterações, ajustes, contribuições dos demais formando (planejamento - grande grupo). Por fim, cada professor formando, que no encontro de formação planejou duas atividades, trabalhava ela com seus estudantes (ação - em sala de aula) para, no encontro seguinte de formação, descrever e discutir o que ocorreu em sua sala de aula (reflexão empírica). Esse ciclo se repete $\mathrm{N}$ vezes, sempre em forma de espiral, em que a cada volta o conhecimento a ser apropriado pela formação vai ganhando corpo e se tornando mais profundo ${ }^{10}$.

As 14 situações-problema contidas no instrumento diagnóstico foram concebidas pensando no esquema multiplicativo elaborado por Magina, Santos e Merlini (2014, 2016), o qual é apresentado na figura 2 a seguir.

\footnotetext{
${ }^{10}$ Para mais detalhes sobre o funcionamento do modelo metodológico Espiral RePARe, ler o artigo "As estruturas multiplicativas e a formação de professores que ensinam matemática na Bahia: um projeto de larga escala”, presente nesta edição.
} 
Figura 2: O esquema elaborado por Magina, Santos e Merlini como releitura do Campo Conceitual Multiplicativo.

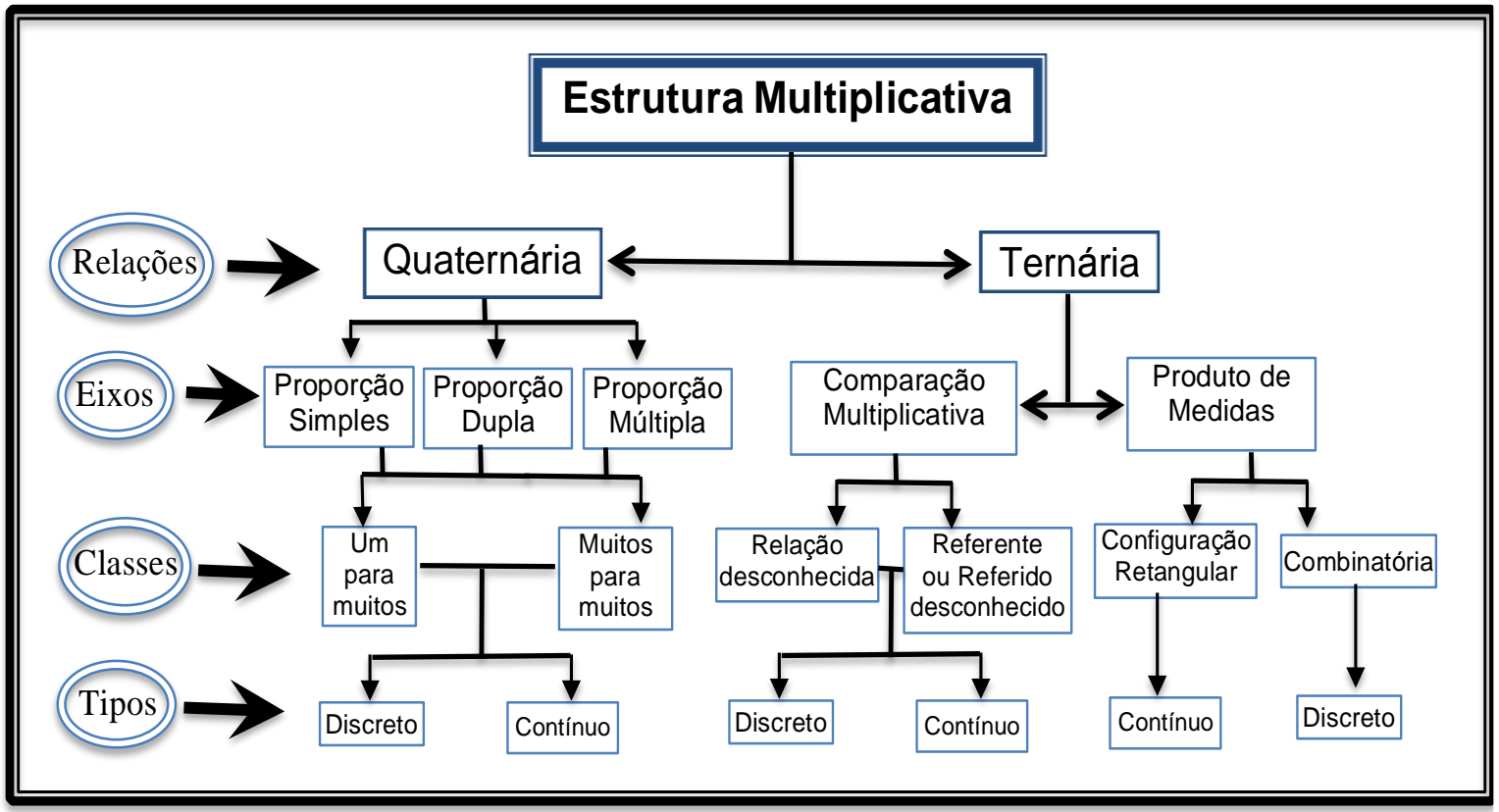

Fonte: Magina, Santos, Merlini $(2014,2016)$

Antes de explicar os elementos presentes no esquema da figura 2, é preciso esclarecer que tal esquema trata de uma releitura das ideias propostas por Vergnaud, no âmbito de sua teoria dos campos conceituais $(1996,2009)$, no que tange ao campo conceitual multiplicativo (VERGNAUD, 1983, 1988, 1994)

Voltando ao esquema da figura 2, notemos que é constituído por duas relações: as quaternárias e as ternárias. A quaternária, por sua vez, é composta por três eixos: proporção simples, proporção dupla e proporção múltipla. Já a segunda relação também é compõe-se por dois eixos: a comparação multiplicativa e o produto de medidas. Os três eixos presentes na relação quaternária possuem duas classes: a de correspondência um para muitos e a de correspondência muitos para muitos, podendo ambas trabalhar com dois tipos de quantidades: discreta e contínua.

Os dois eixos contidos nas relações ternárias têm classes distintas. As classes presentes no eixo da comparação multiplicativa é constituído são: referido e/ou referente desconhecido, e relação desconhecida. Todas as três classe podem trabalhar tanto com os tipos de quantidades discretas quanto contínuas. Por fim, o eixo produto de medida tem como classes a configuração retangular e a combinatória. Devemos salientar que cada uma das duas classes desses eixos só trabalha com um tipo de quantidade: contínua para a configuração retangular e discreta para a combinatória.

Esse esquema tem sido largamente divulgado em textos escritos por pesquisadores participantes desse projeto (GITIRANA ET.AL., 2012, MAGINA, SANTOS, MERLINI, 2014; MAGINA, MERLINI, SANTOS, 2016; SANTANA, LAUTERT, CASTRO, 2017; SOUZA, ISSN 2526-2882 
MAGINA, 2017, apenas para citar alguns dos textos mais recentes) e por isso não vamos discuti-lo a miúde. Porém, como as questões do instrumento diagnóstico estão diretamente relacionadas a ele, ao apresentá-las, na seção que descreverá o método do estudo, relacionaremos cada uma delas com as relações, eixos e classes presentes esquema de Magina, Santos e Merlini (2014), (figura 2).

\section{Método do Estudo}

O estudo que seguiu os princípios da pesquisa descritiva. Tratou-se de uma pesquisa no qual o pesquisador tem por objetivo conhecer e interpretar determinados fenômenos ligados à realidade sem nela interferir para modificá-la (RUDIO, 2001).

Os dados desse estudo foram coletados a partir da aplicação de um instrumento diagnóstico, contendo 14 situações do Campo Conceitual Multiplicativo. Esse instrumento foi aplicado a 4.076 estudantes baianos do Ensino Fundamental (EF), moradores de seis (o6) localizações distintas da Bahia, a saber: Ilhéus/Itabuna, Jequié/Vitoria da Conquista, Amargosa, Feira de Santana, Salvador e Nosso Senhor do Bonfim. Esses estudantes estavam assim distribuídos pelos anos escolares: 408 estudantes do $1^{\circ}$ ano, 371 do $2^{\circ}$ ano, 630 do $3^{\circ}$ ano, 535 do $4^{\circ}$ ano, 689 do $5^{\circ}$ ano, 411 do $6^{\circ}$ ano, 433 do $7^{\circ}, 331$ do $8^{\circ}$ ano e 267 do $9^{\circ}$ ano contidas em um instrumento aplicado a 349 estudantes, de $2^{\mathrm{o}}$ a $5^{\mathrm{a}}$ anos, do Ensino Fundamental. O instrumento foi aplicado coletivamente, sempre com a presença de um pesquisador e o professor de cada turma. Para garantir a compreensão, professor da turma fazia a leitura em voz alta todas as situações. Após esse procedimento, era dado um tempo para que todos os estudantes pudessem responder individualmente cada situação. Do ponto de vista do Esquema de Magina. Santos e Merlini (figura 2), as 14 situações-problema que compuseram esse instrumento estavam assim distribuídas:

Figura 3: As questões do instrumento diagnóstico segundo os eixos e classes propostos no esquema de Magina, Santos e Merlini (2014)

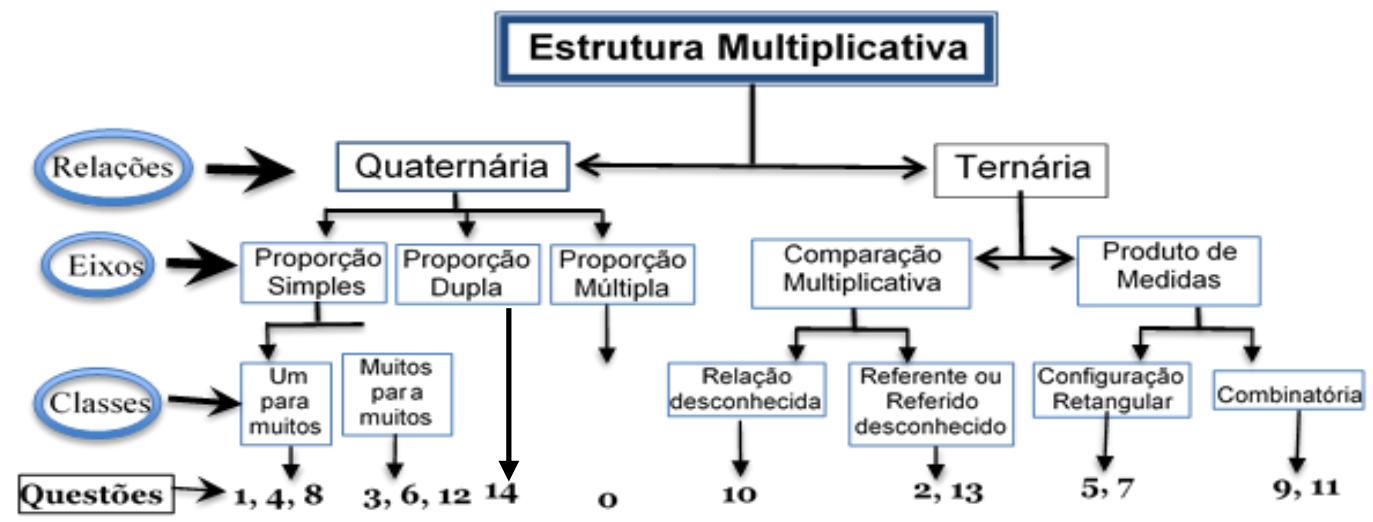

Fonte: Magina, Santos, Merlini (2014)

ISSN 2526-2882 
Na sequência apresentaremos as situações-problema do diagnóstico, segundo seu enquadramento no esquema acima. Salientamos de antemão que o layout dessas situações não serão mantidas em suas apresentações. Porém queremos informar que o instrumento diagnóstico teve dois layouts distintos.

Para os estudantes dos anos iniciais ( $1^{\circ}$ ao $5^{\circ}$ ano) o diagnóstico tinha formato de livrinho, dobrando para tanto uma folha A4. Foram utilizadas quatro folhas A4, dobradas ao meio, formando um livrinho com 8 páginas. Cada folha trazia apenas uma situação. Foi utilizado a frente e o verso da folha. Já o layout do diagnóstico aplicado aos anos finais do Ensino Fundamental ( $6^{\circ}$ ao $9^{\circ}$ ano), em que na $1^{a}$ página havia um cabeçalho e três situações, na segunda e terceira páginas tinham 4 situações cada e na última página ficaram as três últimas situações-problema.

As seis primeiras situações-problema apresentadas na figura, referem-se a situações de relações quaternárias, no âmbito da proporção simples, sendo que as situações 1, 4 e 8 pertencem a classe um-para-muitos, enquanto as situações 3,6 e 12 pertencem a classe muitospara-muitos.

1) JOANA SABE QUE EM UM PACOTE HÁ 6 BISCOITOS. ELA TEM 5 PACOTES. QUANTOS BISCOITOS JOANA TEM?

4) A EsCOLA RECANTO FARÁ UMA FESTA PARA 36 CONVIDADOS. EM CADA MESA FICARÃO 4 CONVIDADOS. QUANTAS MESAS A ESCOLA PRECISARÁ ALUGAR?

8) UM SUPERMERCADO FEZ UMA PROMOÇÃO: “LEVE 4 LITROS DE SUCO POR APENAS 12 REAIS”. QUANTO VAI CUSTAR CADA LITRO DE SUCO?

3) Para fazer 3 Fantasias são necessários 5M DE tecido. ANa tem 35M DE tecido. Quantas FANTASIAS ELA PODE FAZER?

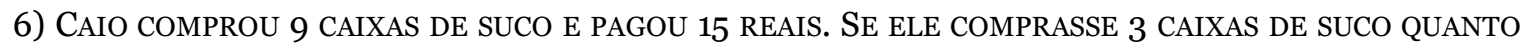
PRECISARIA PAGAR?

12) EM UMA GinCANA NA ESCOla SABER, A CADA 3 VOlTAS CORRENDO NA QUADRA O ALUNO GANHA 4 PONTOS. ALEX DEU 15 VOLTAS CORRENDO NA QUADRA. QUANTOS PONTOS ELE MARCOU?

A Situação-problema 14 também referia-se à uma relação quaternária, porém de proporção dupla. A classe nela envolvida era de um-para-muitos. Trata-se de uma situação com alto grau de dificuldade, seja porque problemas como esse nunca ou quase nunca é trabalhado na escola no Ensino Fundamental, seja porque há várias operações a serem feitas para se chegar em sua solução, seja porque, ainda, que é necessário que o estudante perceba que há três variáveis das quais duas delas tem relação direta com uma terceira, mas não tem entre si. 
14) UMA PESSOA CONSOME, EM MÉDIA, 5 LITROS DE ÁGUA EM DOIS DIAS. QUANTOS LITROS DE ÁGUA UMA FAMÍLIA COMPOSTA POR 4 PESSOAS CONSOMEM EM 6 DIAS?

Apresentamos abaixo um esquema possível para resolver a situação-problema 14, na qual ficam explícitas as duas proporções simples

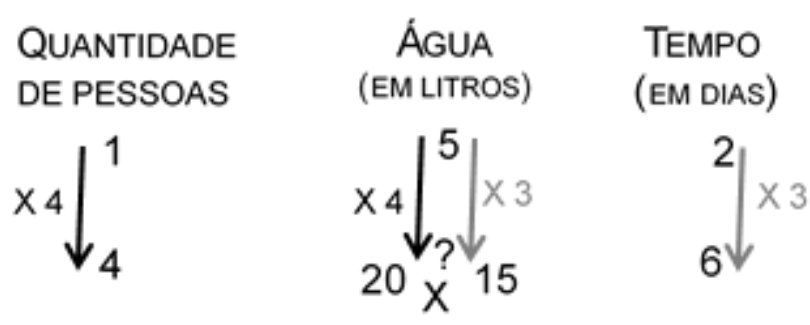

Notemos que existe uma proporção simples, da classe de um-para-muitos, entre a quantidade de pessoas e a de água. Nela está posto, se 1 pessoa consome 5 litros d'água (em 2 dias), então 4 pessoas consumirão 20 litros (em 2 dias). Esse resultado ainda não resolve a situação, é preciso considerar agora o tempo. A variação do tempo interfere no consumo de água (embora não interfira na quantidades de pessoas). Assim temos que se em 2 dias consome-se 5 litros d'água, então em 6 dias serão consumidos 15 litros d'água. Por fim temos que multiplicar os dois resultados encontrados para obter em definitivo o produto do consumo d'água consumidos por 4 pessoas em 6 dias, qual seja 300 litros.

As próximas três situações-problema (2, 10 e 13) tratam de relações terciárias. envolvendo o eixo da comparação multiplicativa, seja das classes relação desconhecida (10) e referido desconhecido ( 2 e 13).

2) A DISTÂNCIA ENTRE A CASA DE LUís E A ESCOLA É DE 5 QUILÔMETROS E A CASA DE JOSÉ É 4 VEZES MAIS DISTANTE. QUAL A DISTÂNCIA ENTRE A CASA DE JOSÉ E A ESCOLA?

10) Cido TEM UMA COLEÇão de 6 CARRINHOS E José TEM UMA COLEÇ̃̃o DE 24 CARRINHOS. QuANTAS VEZES A COLEÇÃO DE CIDO É MENOR DO QUE A DE JOSÉ?

13) ONTEM TONHO TINHA 18 FIGURINHAS. E HOJE ELE TEM 3 VEZES MENOS. QUANTAS FIGURINHAS ELE TEM HOJE? 
Podemos resolver as três situações a partir dos diagramas abaixo apresentados, os quais se relacionam com os elementos da semiótica:

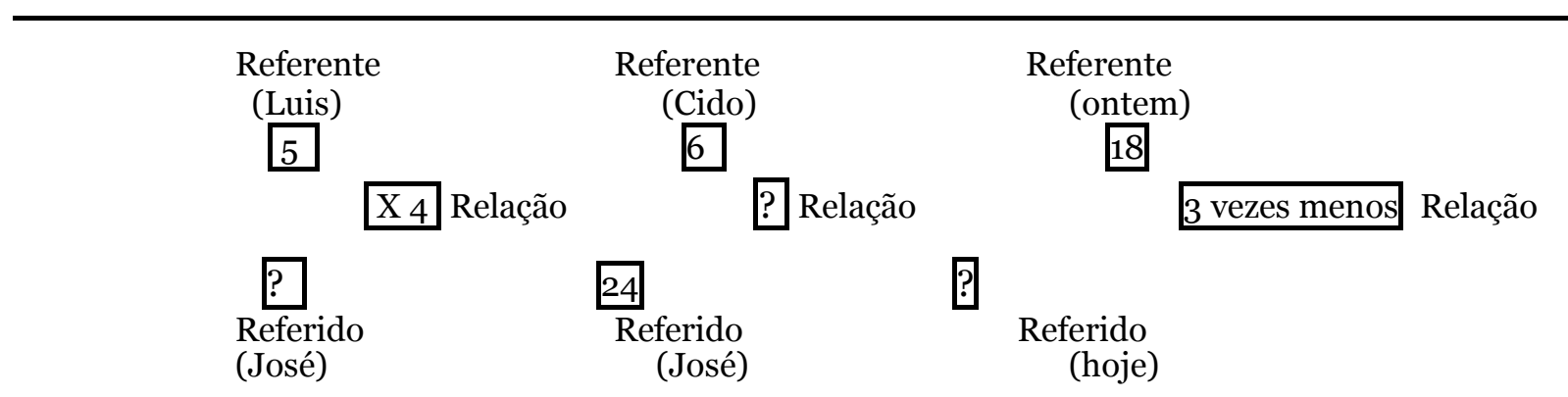

Notemos que enquanto o enunciado da situação-problema 2 tem congruência com a operação a ser realizada para encontrar a resposta, acontece justamente o contrário com os enunciados das outras duas situações, em que na situação-problema 10 o enunciado se refere a "quantas vezes...menor" e na 13 consta " 3 vezes menos". Acontece que a solução dessas duas situações (10 e 13) requer uma operação de divisão. Quando da análise dessas situaçõesproblema poderemos comparar a situação 2 com a 13 e assim observar o quanto a incongruência entre o enunciado e a operação a ser utilizada para sua resolução interfere no sucesso, ou fracasso, da situação.

As próximas duas situações-problema, também envolvendo a Relação Ternária, faz parte do eixo de Produto de Medida e compreende a classe Configuração Retangular (especificamente área)

5) RUTE QUER MUDAR O PISO DO QUARTO DELA. ESTE QUARTO TEM 3M DE LARGURA E 6M DE COMPRIMENTO. QUANTOS METROS QUADRADOS, DE PISO, RUTE PRECISA COMPRAR?

7) A área do Jardim da casa de Vera é retangular e tem 24M². A largura É 4M. Qual é COMPRIMENTO EM METROS DESSE JARDIM?

Notemos que enquanto a situação-problema 5 é informado os dois comprimentos e pede-se a área, ou seja, conhece-se as partes e solicita-se o todo. Ela é facilmente resolvida por meio de uma operação de multiplicação. Já na situação-problema 7 informa-se um dos comprimentos (parte) e a área (todo) e pede-se a outra parte. Para resolvê-la basta proceder com uma operação de divisão. Comparar os desempenhos dos estudantes em uma e outra situação vai nos dar informação sobre a capacidade dos estudantes em lidar com as operações de multiplicação e divisão. 
As próximas duas situações-problema, como as anteriores, também foram elaboradas no âmbito da relação terciária e, ainda, no eixo do Produto de Medida, porém explorando a classe de problema Combinatória.

9) A LANCHONETE DO ERNANI VENDE 15 TIPOS DE SANDUíCHES. PARA CADA SANDUÍCHE É USADO APENAS UM TIPO DE PÃO E UM TIPO DE RECHEIO. TEM 3 TIPOS DE PÃO (LEITE, INTEGRAL E FRANCÊS). QUANTOS TIPOS DE RECHEIO SÃO NECESSÁRIOS PARA FAZER TODOS OS TIPOS DE SANDUÍCHES?

11) NA AUla DE DANÇA DE FORRÓ TINHA 6 RAPAZES (AlEX, BETO, CAIO, DAVI, EDU, IVo) E 4 MoÇAS (MARI, FABI, LARA, SUZI). TODAS AS MOÇAS DANÇARAM COM TODOS OS RAPAZES. QUANTOS CASAIS DIFERENTES FORAM FORMADOS?

Igualmente às últimas duas situações discutidas, aqui também temos a situaçãoproblema 11 em que temos as partes e solicitamos o todo (os pares) e cuja resolução requer uma operação de multiplicação, e a situação-problema 9, que informa a quantidade de grupo de elementos e a combinação e solicita a quantidade do outro grupo. Nesse caso a operação requerida é a divisão.

Tendo apresentado todas as situações-problema do instrumento diagnóstico, passaremos a apresentar os resultados dos estudantes ao resolvê-las. Já esclarecemos que todos os dados serão sempre apresentados considerando os anos escolar (do $1^{\circ}$ ao $9^{\circ}$ ano).

\section{Resultados Quantitativos do Estudo}

O primeiro resultado que apresentamos no gráfico 1 refere-se ao percentual geral de acerto dos estudantes nas situações-problema do instrumento, por ano escolar.

Gráfico 1: Desempenho geral dos estudantes, por ano escolar.

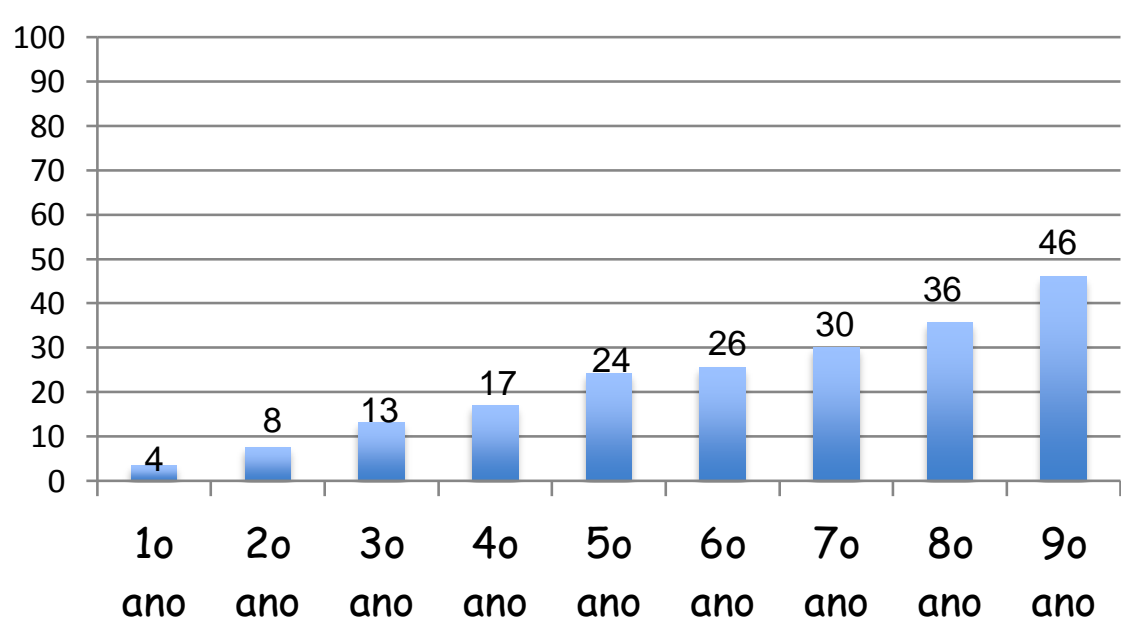

Fonte: dados da pesquisa 
Os números contidos no gráfico 1 apresentam resultados desanimadores, em que embora haja um crescimento no percentual de acerto entre anos escolares e que o $9^{\circ}$ ano teve um desempenho 10 vezes maior que o $1^{\circ}$ ano, o crescimento é pífio, menos de $10 \%$ de um ano para outro, com exceção da diferença entre o $8^{\circ}$ e $9^{\circ}$ ano, que chega a ser exatos $10 \%$. Nenhum dos anos atingiu percentual médio de acerto igual ou superior a 50\% do instrumento, num claro indicador de que esses estudantes ainda não se apropriaram dos conceitos envolvidos nas estruturas multiplicativas. Isto significa que muito trabalho ainda é requerido dos educadores para que nossos estudantes possam dominar tal estrutura.

De fato, nós não tínhamos expectativas positivas para os percentuais de acerto dos $1^{\circ}$, $2^{\circ}$ e $3^{\circ}$ anos, uma vez que as operações de multiplicação e divisão só costumam serem introduzidas a partir do $3^{\circ}$ ano. Contudo constatar que menos de $1 / 4$ das possíveis respostas corretas entre os estudantes que se encontravam concluindo os anos iniciais do Ensino Fundamental. Igualmente desolador é constatar que o percentual médio de acertos entre estudantes do $7^{\circ}$ ano, que já estão sendo introduzidos na álgebra, foi meros 30\%. O que está acontecendo? Quais problemas os problemas que eles acertam?

O instrumento, porém, foi elaborado levando em consideração os cinco eixos, e faz necessário que olhemos para o desempenho dos estudantes em cada um desses eixos (exceto o eixo da proporção múltipla).

O primeiro eixo a passar por nossa análise é o de proporção simples. Nesse caso examinaremos conjuntamente, as classes um-para-muitos e muitos-para-muitos. Lembramos que havia no instrumento três situações-problema envolvendo a classe de um-para-muitos (questões 1, 4 e 8) e, igualmente, havia outras três que pertenciam a classe de muitos-paramuita (questões 3, 6 e 12). O gráfico 2 apresenta os percentuais médios de acerto em cada uma dessas situações, considerando os anos escolares.

Gráfico 2: O desempenho dos estudantes em situações-problema do eixo proporção simples, por ano escolar

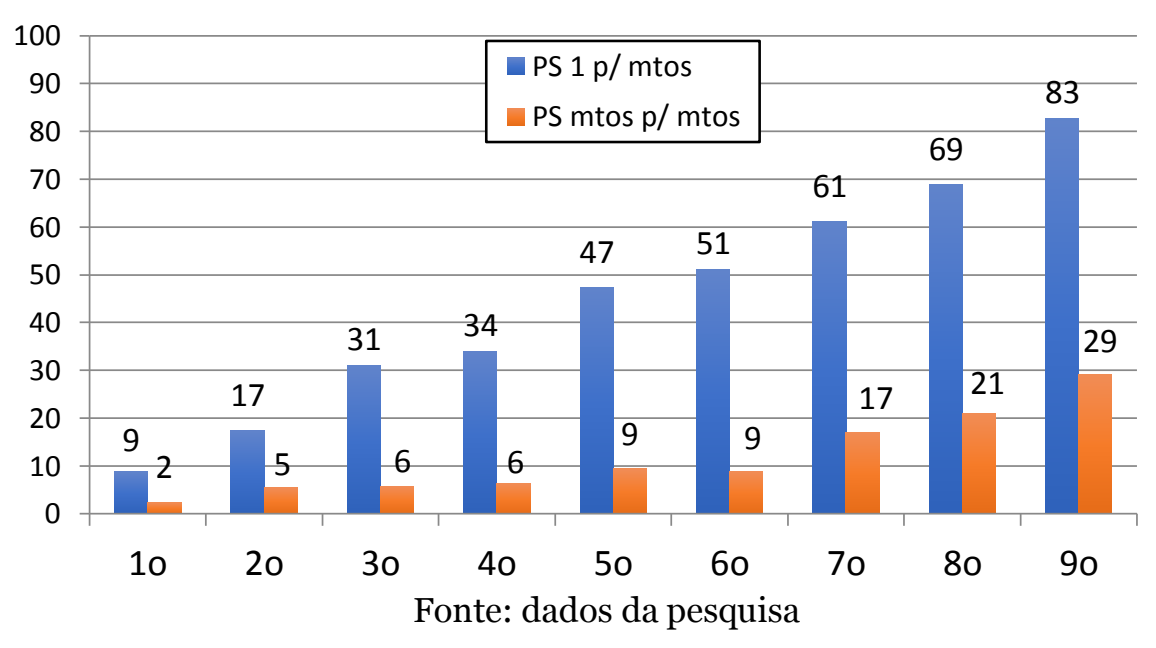

ISSN 2526-2882 
Os resultados expostos no gráfico 2 mostram uma grande discrepância entre os desempenhos dos estudantes de uma classe para outra, em favor da classe um-para-muitos. Tal já é notado desde o $1^{\circ}$ ano e vai se acentuando cada vez mais até chegar ao ápice no $9^{\circ}$ ano.

Um primeiro olhar mais descuidado poderia explicar tal diferença pelo fato que a classe de muitos-para-muitos envolver ambas as operações multiplicação e divisão (é o que a escola chama de $4^{\text {a }}$ proporcional). Porém é importante ter em mente que em todas três situações os valores numéricos são muito pequenos e a que envolve a maior proporção é a relação entre 35 e 5 (35 é 7 vezes 5). Assim, podemos dizer que todas as relações proporcionais cabem dentro das tabuadas até 9, aquelas bastante conhecidas e exploradas na escola. Então não se justifica percentuais de acertos tão baixos. Entre o $5^{\circ}$ e $9^{\circ}$ ano o crescimento no percentual médio de acerto foi de apenas $20 \%$ e o que é mais grave, o percentual de acerto do $9^{\circ}$ ano foi de pífios $29 \%$.

Quando olhamos apenas para os resultados relacionados a classe de um-para-muitos, notamos que há um grande crescimento nas médias dos desempenhos dos estudantes de um ano escolar para outro, culminando com a $83 \%$ de acertos no $9^{\circ}$ ano. Contudo o percentual de acerto dos estudantes do $5^{\circ}$ ano, o último dos anos iniciais, não atingiu os $50 \%$ nessa classe, o que em si é bastante preocupante. O Gráfico 3 a seguir apresenta os comportamentos desses estudantes em cada uma das situações, para que assim, possamos observá-las melhor.

Gráfico 3: O desempenho dos estudantes em situações-problema do eixo proporção simples, classe um-para-muitos, por ano escolar

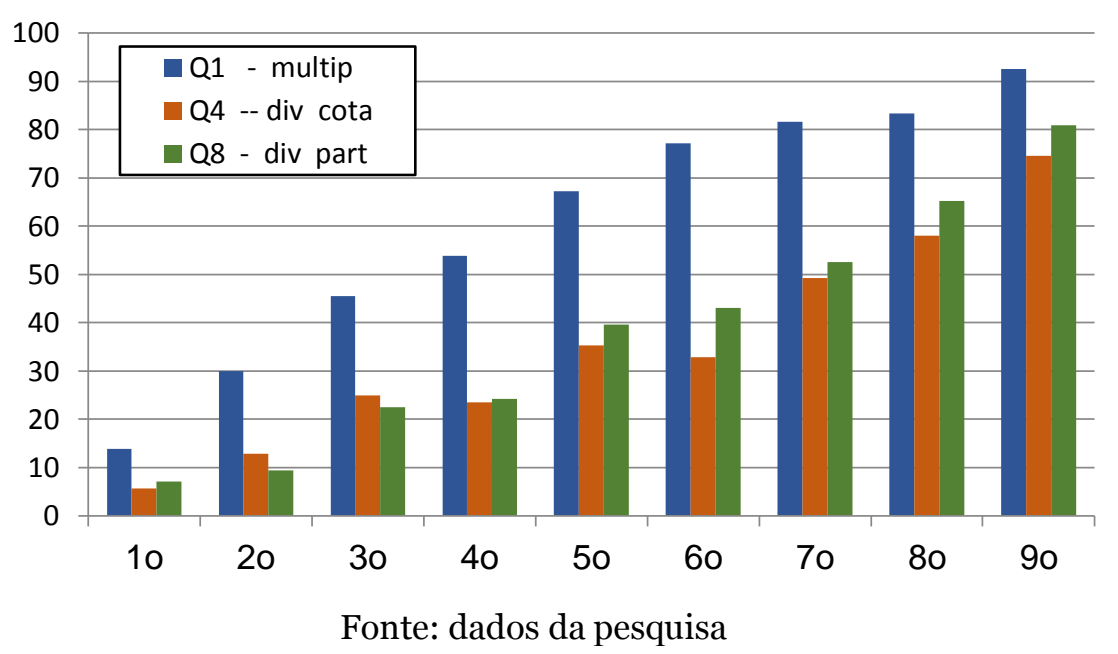

Notemos que apenas no $7^{\circ}$ anos é que temos 50\% dos estudantes hábeis para resolver situações-problema de divisão, enquanto que $30 \%$ dos estudantes do $2^{\circ}$ ano já se mostram capazes de terem sucesso em lidar com situações multiplicativas. Até que ponto a escola tem identificado tais comportamento? 
Do nosso ponto de vista, tais dados denotam que ainda será preciso realizarmos um trabalho bem mais efetivo nos anos iniciais para ajudar os estudantes desse período a se apropriarem das estruturas multiplicativas, principalmente no que tange à operação de divisão. Para tal propomos irmos muito mais adiante do que fazer nossos estudantes memorizar as tabuadas; Avançar para além de apenas treinar os algoritmos das operações de multiplicação e divisão. É preciso que os estudantes lidem com um vasto universo de situações de tal maneira a contribuir para a formação dos conceitos referentes a esses dois conteúdos. E para tal o professor tem uma importante função, pois ele é o mediador entre o conhecimento e o estudante, cabendo a ele diversificar as situações e questionar, sempre que pertinente, seus estudantes sobre os conceitos presentes em cada uma delas. Além disso, é preciso que o professor tenha sempre em mente que o processo de aprendizado, longe de ser linear, transita entre idas e vindas.

Esses resultados coadunam com aqueles encontrados por Magina, Santos, Merlini (2014), ao compararem os desempenhos de estudantes do $3^{\circ}$ e $5^{\circ}$ anos em duas situaçõesproblema de proporção simples, sendo uma da classe um-para-muitos e outra de muitos-paramuitos. Concluiram esses autores que:

\begin{abstract}
se considerarmos o sucesso dos estudantes como indicador de aprendizagem, os resultados indicam que houve pouco ganho quando comparamos o desempenho dos estudantes dos 30 e 50 anos em problemas que envolvem a classe muitos para muitos dentro do eixo Proporção simples (Q2). Esse dado é preocupante, pois era esperado que houvesse uma nítida evolução nesses percentuais, uma vez que dois anos letivos separam um grupo do outro. Tal evolução é nítida apenas na Q1. Um avanço entre os percentuais de sucesso dos dois grupos de estudantes nos dois problemas indicaria que a escola está atenta para a necessidade de expandir o Campo Conceitual com eles, não se limitando em trabalhar apenas as situações que permitam explorar a continuidade entre o raciocínio aditivo e multiplicativo. (MAGINA, SANTOS, MERLINI, 532)
\end{abstract}

Por fim ainda dentro das relações quaternárias há a situação-problema 14, que pertence ao eixo proporção dupla, dentro da classe um-para-muitos. Nós já tínhamos previsto que os percentuais de acertos seriam baixos e isso realmente aconteceu. De fato, os estudantes chegam ao $5^{\circ}$ ano com irrisório percentual de acerto de 2,5\%, o que faz bastante sentido pelos motivos que já havíamos mencionado quando apresentamos a situação-problema. Já entre os estudantes dos anos finais os desempenhos foram 7,8; 5,8; 12,4 e 23,6 (para os 6o $7^{\circ}, 8^{\circ}$ e $9^{\circ}$ anos), o que também foram resultados muito inexpressivos, principalmente se considerarmos que os estudantes do $7^{\circ}$ e $8^{\circ}$ anos, já viram conceitos tão sofisticados como a álgebra e a função.

Na sequência, passaremos a discutir os resultados dos estudantes em situaçõesproblema dentro das relações ternárias. Iniciaremos por aquelas classificadas no eixo de Comparação Multiplicativa.

$$
\begin{aligned}
& \text { I I } \angle J \angle 0-\angle O O< \\
& 65
\end{aligned}
$$


Gráfico 4: Desempenhos dos estudantes nas três situações-problema do eixo da Comparação Muliplicativa, segundo o ano escolar

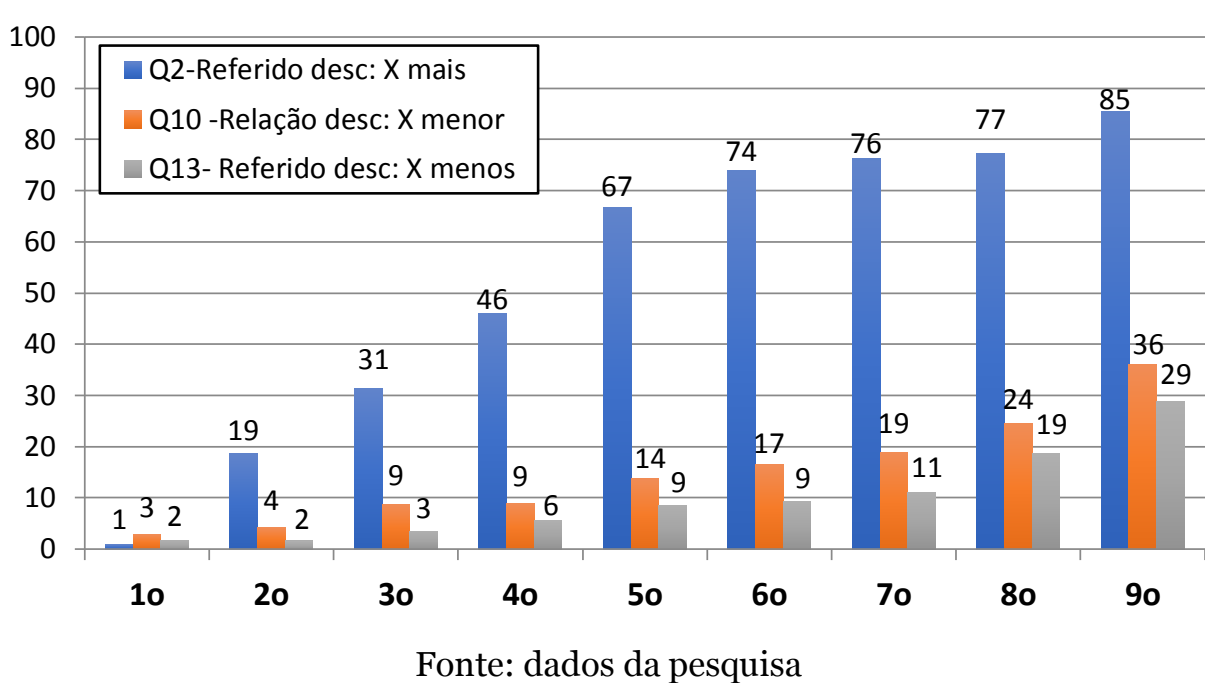

Os resultados dos estudantes de todos os anos, com exceção do $1^{\circ}$, seguiram uma mesma tendência, apresentando um desempenho bem melhor na questão em que o referido era desconhecido e, além disso, tratava-se de uma situação que requeria a operação de multiplicação para sua resolução. A partir do $5^{\circ}$ ano, a média percentual de acerto ultrapassa 2/3 de todas as respostas dos estudantes de cada ano, chegando a atingir a boa média de mais de 4/5 no $9^{\circ}$ ano. O que chama atenção é que a media percentual de acerto dos estudantes de todos os anos na situação-problema 13 é muito ruim, chegando ao final dos anos iniciais $\left(5^{\circ}\right.$ ano) com pífios $9 \%$ e não conseguem atingir 30\% de sucesso na questão os estudantes concluintes o Ensino Fundamental. Todas duas questões são da mesma classe (referido desconhecido), com uma única diferença, enquanto no enunciado da situação 2 está escrito “quantas vezes mais”, sendo a operação requerida é multiplicação, no enunciado da situação 13 está escrito “ 3 vezes mais”, sendo que a operação requerida é a divisão.

Tal fato parece fazer toda a diferença e vem ao encontro dos resultados encontrados por Magina \& Santana (2015) quando pesquisaram os desempenhos de estudantes do $3^{\circ}$ anos do Ensino Fundamental, quando esses tentavam resolver quatro situações aditivas, sendo duas do que Magina chamou de $1^{\mathrm{a}}$ extensão (cognitivamente mais simples) e outras duas de $3^{\mathrm{a}}$ extensão (cognitivamente mais complexa). Em cada uma dessas extensões tinha uma situaçãoproblema em que o enunciado era congruente com a operação a ser usada para resolve-la e outra situação-problema em que havia incongruência entre as palavras do enunciado e a operação requerida para solucioná-la. O sucesso desses estudantes nas situações de $1^{\mathrm{a}}$ extensão em que o enunciado era incongruente foi muito próximo ao seu sucesso na situação-problema

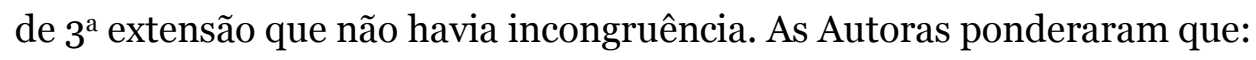

Esses resultados nos permitem pensar que a incongruência exerceu forte 
influência no desempenho desses estudantes. Tal influência se mostrou tão efetiva a ponto de não provocar diferença significativa entre o desempenho dos alunos numa questão com incongruência de 1a extensão e na questão de 3a extensão sem incongruência. Em outras palavras, parece que a incongruência foi um fator de dificuldade tão grande que o desempenho dos estudantes em um problema classificado como de 1a extensão, quando o ser enunciado apresentava incongruência com a operação a ser utilizada, ficou no mesmo níveis de acertos que no problema de 3 a extensão em que o enunciado era congruente com a operação. (MAGINA, SANTANA, 2015, p. 9).

Podemos nos utilizar desse mesmo argumento para explicar as diferenças encontradas entre as situações-problema 2 e 13 de nosso instrumento e isso foi válido para os estudantes de todos os anos escolares, exceto o $1^{\circ}$. Ainda corroborando com a posição de Magina \& Santana (2015) os estudantes tenham obtido percentual de acerto melhor na situação-problema 10 que na 13, essa diferença não atingiu os 10\%. E, novamente, vemos no enunciado dessa situação uma expressão que pode ter induzido os estudantes ao erro na escolha da operação, qual seja, "QuANTAS VEZES A COLEÇão DE CIDO É MENOR” (grifo nosso). Arriscamos a conjecturar que o termo "menor" interferiu menos que o termo "menos", presente na situação-problema 13 .

Tal resultado nos faz pensar sobre a importância das palavras na construção dos problemas e mais, o perigo de relacionar uma operação a algumas palavras, tais como "aumentar, ganhar, somar, receber", indicam que é preciso realizar uma conta de adição; já os termos "perder, dar, emprestar, menos" indicam que é preciso realizar uma operação de subtração, e assim por diante.

O ensino das operações por meio de palavras "dicas” pode ser muito prejudicial a formação do conceito do estudante.

O próximo grupo de situações-problema que analisaremos diz respeito ao eixo do Produto de Medidas, dentro da classe Configuração Retangular (especificamente, a área). O instrumento tinha duas situações, a $5^{\mathrm{a}}$ e a $7^{\mathrm{a}}$. A $5^{\mathrm{a}}$ situação-problema oferecia os dois comprimentos de um retângulo e solicitava a área desse retângulo, requerendo, portanto, de apenas encontrar o produto entre essas duas medidas. Podemos então pensar que nessa questão era informado as partes (da área) e solicitava o todo (a própria área). Já a situaçãoproblema 7 informava um dos comprimentos de um dos lados de uma área retangular e também a própria área desse retângulo e solicitava a medida do outro comprimento. Para resolver essa situação bastava realizar uma operação dividindo a área pelo comprimento do lado informado. Nesse caso podemos pensar que foi informado uma das partes e o todo (a área). O gráfico 5 a seguir apresenta as médias dos desempenhos dos estudantes em cada uma das questões. 
Gráfico 5: Desempenhos dos estudantes nas duas situações-problema do eixo Produto de Medidas, classe Configuração Retangular, segundo o ano escolar.

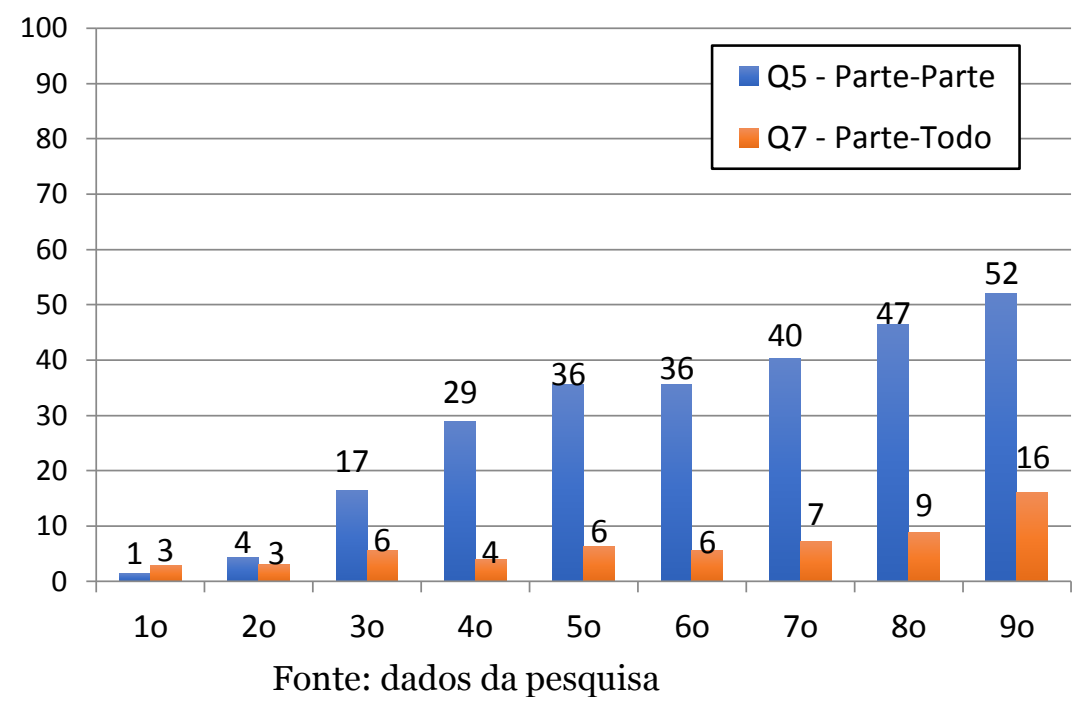

Mais uma vez notamos que quando a situação-problema pode ser resolvida por meio da multiplicação o sucesso dos estudantes é bem maior que quando é preciso realizar uma operação de divisão. Isso foi fato para todos os anos, exceto para os $1^{\circ} \mathrm{e} 2^{\circ}$ anos, que certamente ainda não aprenderam essas duas operações formalmente e os que resolveram o fizeram intuitivamente, por meios alternativos, utilizando como apoio ícones e adição ou subtração. $\mathrm{O}$ que nos chama muito atenção é que a Base Nacional Curricular Comum (BNCC) (BRASIL 2017) propões que tal conceito seja trabalhado desde o $4^{\circ}$ ano. Igualmente, o Parâmetro Curricular Nacional (PCN) (BRASIL, 1997) propõe que tal conteúdo seja introduzido no $2^{\circ}$ ciclo do Ensino Fundamental ( $4^{\circ}$ e $5^{\circ}$ anos na nomenclatura vigente). Mas parece que estamos longe de atender tal proposta, já que apenas $36 \%$ dos estudantes do $5^{\circ}$ ano tem êxito em tal problema, e isso se considerarmos apenas a situação em que a operação de multiplicação é requerida, porque a que requer a divisão teve o pífio resultado de $16 \%$ de acerto no $9^{\circ}$ ano! Analisaremos tal comportamento a partir dos resultados dos estudantes diante das duas situações de combinatória a seguir, já que elas seguem a mesma lógica dessas duas de área, qual seja, uma situação que requer a multiplicação para resolver e outra que necessita de uma divisão.

O Gráfico 6 a seguir apresenta as médias dos desempenhos dos estudantes nas duas situações-problema de combinatória, sendo que uma (11 $\left.{ }^{\mathrm{a}}\right)$ informa as duas partes e solicita a combinação entre elas (o todo), enquanto a outra (situação $9^{\text {a) }}$ informa sobre o total de possibilidades e um dos conjuntos e solicita saber a quantidade do outro conjunto. 
Gráfico 6: Desempenhos dos estudantes nas duas situações-problema do eixo Produto de Medidas, classe Combinatória, segundo o ano escolar.

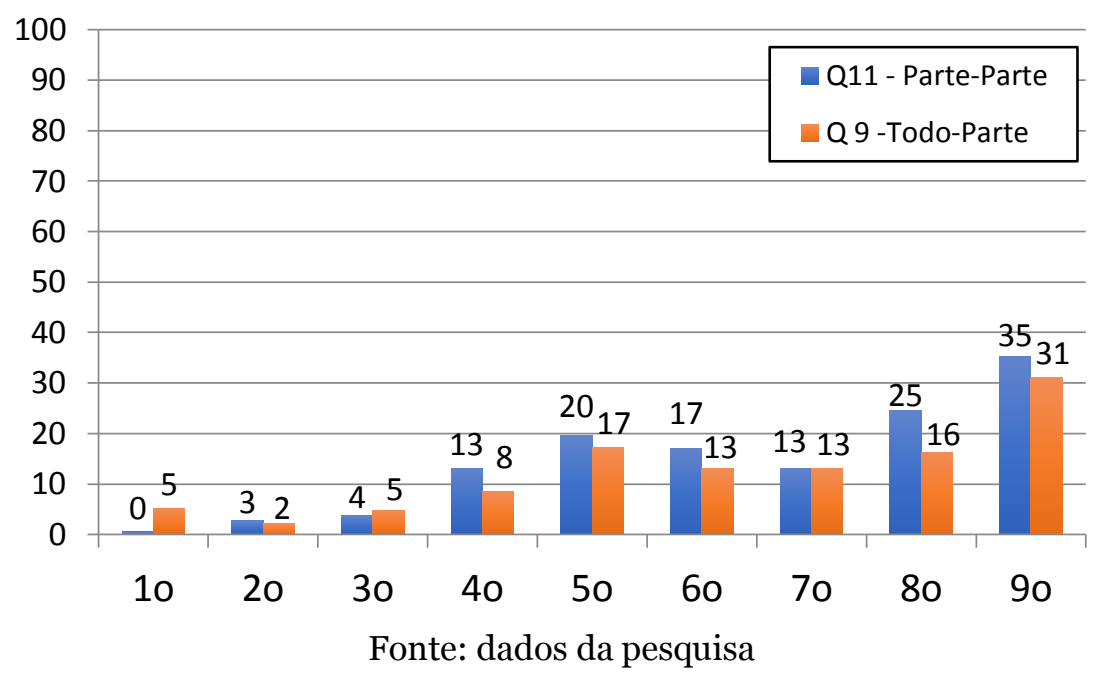

Os dados apresentados no Gráfico 6 é ainda um pouco mais desanimador que aqueles apresentados no Gráfico 4, já que aqui os estudantes não têm sucesso na resolução de nenhuma das duas situações. Eles atem acertam um pouco mais na situação que informa o todo e a parte, solicitando a outra parte (Q9), mas esse acerto tem seu ápice no $9^{\circ}$ ano, com apenas $31 \%$ dos estudantes tendo sucesso na sua resolução. Por outro lado, a situação em que são apresentados as duas partes (os dois conjuntos a serem combinados) e solicita-se a combinação (o todo), os estudantes de todos os anos se saem pior do que na situação-problema 5. A conclusão a que podemos chegar é que a grande maioria esses estudantes ainda não se apropriaram do conceito de combinatória. e isto vale para todos os anos do Ensino Fundamental.

\section{Considerações Finais}

Chegamos ao final deste artigo com uma visão da competência dos estudantes do Ensino Fundamental muito pessimista. Tal visão é ainda mais pessimista quando pensamos em situações-problema que envolvam a operação de divisão.

Reconhecemos que para mais bem avaliar esses pífios desempenhos apresentados em quase todas as situações (proporção simples, classe muitos-para-muitos, comparação multiplicativa, classe relação desconhecida, produto de medidas, classe configuração retangular, em especial quando se conhece a área e uma das partes e solicita-se a outra parte, e combinatória), será preciso analisar os esquemas de ação utilizados por esses estudantes ao lidarem com as situações do diagnóstico. Esta não foi a nossa proposta neste momento. De fato, pretendemos apenas dar uma visão geral dos desempenhos desses estudantes no 
instrumento. E o que identificamos é que eles ainda precisam avançar muito na apropriação desse campo conceitual.

Considerando que o instrumento foi aplicado em 4076 estudantes, advindos de seis diferentes regiões da Bahia, nossa hipótese é que esse quadro representa o comportamento dos estudantes baianos.

Concluímos este artigo alertando os educadores para a fragilidade dos conceitos de multiplicação, de proporção simples (principalmente a proporcionalidade simples de muitospara-muitos) e, mais ainda, de divisão, de área e de sobre maneira, de combinatória, dos estudantes de todo o Ensino Fundamental. E mais, propomos que políticas públicas, estaduais e municipais, sejam adotadas no sentido de ampliar, de maneira sólida e efetiva, a formação dos conceitos pertencentes às estruturas multiplicativas.

\section{Referências}

BRASIL, Secretaria de Educação Fundamental. Parâmetros Curriculares Nacionais: Introdução aos Parâmetros Curriculares Nacionais / Secretaria de Educação Fundamental. Brasília: MEC / SEF, 1997.

. Secretaria de Educação Básica. Base Nacional Comum Curricular. Brasília: MEC/SEB, 2017.

GITIRANA, V.; CAMPOS, T.; MAGINA, S.; SPINILLO, A. Repensando Multiplicação e Divisão: Contribuições da Teoria dos Campos Conceituais. São Paulo: PROEM, 2014.

MAGINA, S. (Re)significar as estruturas multiplicativas a partir da formação 'ação-reflexão-planejamento-ação' do professor. Projeto de Pesquisa. Brasília: CNPq. 2008.

A Teoria dos Campos Conceituais: contribuições da Psicologia para a prática docente. Educar Em Revista. Curitiba, 2011.

As estruturas multiplicativas e a formação de professores que ensinam matemática na Bahia. Projeto de Pesquisa. Salvador: FAPESB: 2013

MAGINA, S; SANTANA, E. A incongruência entre as palavras do enunciado do problema e a operação usada para resovê-lo: uma contribuição para o debate. In Conferência Iberoamericana de Educacion Matemática - XIV CIAEM: Mexico, Chiapas, p. 1-11, 2015

MAGINA, Sandra, SANTOS, Aparecido, MERLINI, Vera. O raciocínio de Estudantes do ensino fundamental na resolução de situações das estruturas multiplicativas. Ciência \& Educação, Bauru, v. 20, No 2, 2014, p. 517-533.

A estrutura multiplicativa à luz da teoria dos campos conceituais: uma visão com foco na aprendizagem. In Castro Filho, Jose; Barreto, Marcília; Barguil, Paulo; Maia, Dennys; Pinheiro Joserlene (Eds.) Matemática, Cultura e Tecnologia: perspectivas internacionais. Curitiba: CRV, p. 65-82, 2016. 
RUDIO, F. Introdução ao Projeto de Pesquisa Científica. Petrópolis: Vozes, $32^{\text {a }}$ ed, 2001.

SANTANA, E; LAUTERT, S; CASTRO FILHO, J (Org.). Ensinando multiplicação e divisão: $4^{o}$ e $5^{o}$ anos. Itabuna, BA: Via Litterarum, 2017.

SOUZA, E; MAGINA, S. A Concepção de Professor do Ensino Fundamental sobre Estruturas Multiplicativas. Perspectiva da Educação Matemática, UFMT: Campo Grande, pp.816-833, 2017

VERGNAUD, G. Multiplicative structures. In: LESH, R.; LANDAU M. (Eds.). Acquisitions of mathematics concepts and procedures. New York: Academic Press, pp.127$174,1983$.

. Multiplicative structures. In: HIEBERT, H.; BEHR, M. (Ed.). Research Agenda in Mathematics Education. Number Concepts and Operations in the Middle Grades. Hillsdale, N.J.: Lawrence Erlbaum, p. 141-161, 1988.

- La théorie des champs conceptuels. Recherches en Didactique des Mathématiques. Grenoble, v. 10, n. 23, p. 133-170, 1990.

- Multiplicative conceptual field: what and why? In: GUERSHON, H.; CONFREY, J. (Eds.). The development of multiplicative reasoning in the learning of mathematics. Albany, N.Y.: State University of New York Press, p. 41-59, 1994.

A criança, a Matemática e a Realidade: problemas do ensino da matemática na escolar elementar. trad. Maria Lucia Moro. Curitiba: ed. UFPR, 2009

\section{Agradecimentos}

A autora Sandra Magina agradece os importantes apoios recebidos pelas agências FAPESB (por meio do termo de outorga PESoo19/2013) e CNPq (por meio da bolsa Pq)

\section{Biografia Resumida}

Sandra Maria Pinto Magina. Bacharel em Psicologia pela UFPE; Mestre em Psicologia Cognitiva pela UFPE; doutora em Educação Matemática pela London University; pós-doutora em

$$
\text { ISSN 2526-2882 }
$$


Educação Matemática pela Universidade de Lisboa. Professora Adjunto da Universidade de Santa Cruz (UESC-BA), docente dos programas de Pós-Grauação em Educação Matemática e em Educação da UESC; Lider do grupo de Pesquisa RePARe.

Link do Lattes: http://lattes.cnpq.br/8948168068305523

e-mail: sandramagina@gmail.com

Sônia Pereira da Fonseca. Bacharel em Administração pela Faculdade Campos Elíseos (FCE) e em Economia pela UNIT/SE. Mestre em Administração pela FGV/SP. Doutora em Educação pela PUC/SP. Professora Adjunto da Universidade de Santa Cruz (UESC-BA). Docente dos programas de PósGraduação em Educação da UESC. Membro do grupo de Pesquisa RePARe.

Link Lattes: http://lattes.cnpq.br/0463654957762860

e-mail: soniafonseca19@gmail.com 